\title{
A generic method of engagement to elicit regional coastal management options
}

\author{
Catherine M. Dichmont ${ }^{1}$, Leo X.C. Dutra ${ }^{2,3}$, Randall Owens ${ }^{4}$, Eddie Jebreen ${ }^{5}$, \\ Carolyn Thompson ${ }^{6}$, Roy A. Deng2 , Elizabeth I. van Putten7 ${ }^{7}$, Ricardo Pascual2, \\ Jeffrey M. Dambacher ${ }^{7}$, Michael St. J. Warne ${ }^{8}$, Ross H. Quinn' ${ }^{5}$, Olivier Thébaud ${ }^{1,9}$, \\ John Bennett ${ }^{10}$, Mark Read ${ }^{4}$, David Wachenfeld ${ }^{4}$, Julia Davies ${ }^{5}$, Anna Garland ${ }^{5}$, \\ Malcolm Dunning ${ }^{5}$, Catherine Collier ${ }^{11}$, Michelle Waycott ${ }^{12}$, Julia Playford ${ }^{8}$
}

${ }^{1}$ CSIRO Oceans and Atmosphere, Ecosciences Precinct, 41 Boggo Rd, Dutton Park, Queensland, 4102, Australia; cathy.dichmont@csiro.au; +61 738335629

${ }^{1}$ Corresponding author

${ }^{2}$ CSIRO Oceans and Atmosphere, Queensland Bioscience Precinct, 306 Carmody Road, St Lucia, Queensland, 4067, Australia

${ }^{3}$ School of Marine Studies, Faculty of Science, Technology \& Environment, The University of the South Pacific - Laucala Bay Road, Suva, Fiji Islands

${ }^{4}$ Great Barrier Reef Marine Park Authority, 2-68 Flinders Street, PO Box 1379, Townsville, QLD, 4810,

Australia

${ }^{5}$ Queensland Department of Agriculture and Fisheries, Primary Industries Building, 80 Ann St, Brisbane, QLD, 4001, Australia

${ }^{6}$ Great Barrier Reef Marine Park Authority, 43 River Street, Mackay, QLD 4740, Australia

${ }^{7}$ CSIRO Oceans and Atmosphere, GPO Box 1538, Hobart, TAS, 7001, Australia.

${ }^{8}$ Queensland Department of Science, Information Technology and Innovation, Ecosciences Precinct, 41

Boggo Rd, Dutton Park, Queensland, 4102, Australia

9Ifremer, UMR M101, AMURE, Unité d'Economie Maritime, BP 70, F-29280 Plouzané Cedex, France

${ }^{10}$ Queensland Department of Environment and Heritage Protection, Ecosciences Precinct, 41 Boggo Rd, Dutton Park, Queensland, 4102, Australia

${ }^{11}$ Centre for Tropical Water \& Aquatic Ecosystem Research (TropWATER), James Cook University, Cairns, Queensland 4870, Australia

12University of Adelaide, School of Biological Sciences, Environment Institute, University of Adelaide, Adelaide, SA, 5005, Australia. 


\section{1. Abstract}

2 Stakeholder engagement is important for successful management of natural

3 resources, both to make effective decisions and to obtain support. However, in

4 the context of coastal management, questions remain unanswered on how to

5 effectively link decisions made at the catchment level with objectives for marine

6 biodiversity and fisheries productivity. Moreover, there is much uncertainty on

7 how to best elicit community input in a rigorous manner that supports

8 management decisions. A decision support process is described that uses the

9 adaptive management loop as its basis to elicit management objectives, priorities

10 and management options using two case studies in the Great Barrier Reef,

11 Australia. The approach described is then generalised for international interest.

12 A hierarchical engagement model of local stakeholders, regional and senior

13 managers is used. The result is a semi-quantitative generic elicitation framework

14 that ultimately provides a prioritised list of management options in the context

15 of clearly articulated management objectives that has widespread application for

16 coastal communities worldwide.

17 The case studies show that demand for local input and regional management is

18 high, but local influences affect the relative success of both engagement

19 processes and uptake by managers. Differences between case study outcomes

20 highlight the importance of discussing objectives prior to suggesting

21 management actions, and avoiding or minimising conflicts at the early stages of

22 the process. Strong contributors to success are a) the provision of local

23 information to the community group, and b) the early inclusion of senior 
24 managers and influencers in the group to ensure the intellectual and time

25 investment is not compromised at the final stages of the process.

26 The project has uncovered a conundrum in the significant gap between the way

27 managers perceive their management actions and outcomes, and community's

28 perception of the effectiveness (and wisdom) of these same management actions.

\section{2. Keywords}

30 Regional management; community engagement; generic framework;

31 management strategies; objective weights

\section{Introduction}

33 Pressure on ecosystems in the coastal zone has increased with time due to

34 population growth and the social and economic importance of these areas

35 (Halpern et al., 2009). Effective management of this zone is important as they

36 contain many iconic and threatened species (such as dugongs, water birds,

37 turtles) and also key habitats (wetlands, seagrasses, mangroves).

38 The coastal zone of the Great Barrier Reef in Australia experiences the impacts of

39 cumulative effects, most notably inputs of sediment, nutrient and contaminants

40 from rural and urban land sources (Kroon et al., 2013). However, managing

41 cumulative impacts can be seen as a "wicked" problem because interactions

42 within and among the social, economic and ecological systems are highly

43 complex, non-linear and mostly unknown, which has often led to management

44 failure (Ludwig, 2001; Rittel and Webber, 1973). Science is categorised as only

45 being able to solve "tame" problems (Rittel and Webber, 1973). 
46 Two solutions have been put forward to address this dilemma: a) Adaptive

47 management, which involves iterative decision making, via evaluating the

48 outcomes from previous decisions and adjusting subsequent actions on the basis

49 of this evaluation (Sainsbury et al., 2000; Walters and Hilborn, 1976), and b)

50 effective stakeholder engagement to facilitate social learning improving

51 outcomes (Muro and Jeffrey, 2008). If these two processes are combined, they

52 form essential foundational steps to achieve effective environmental

53 management, through good information, development of identity, and

54 institutions and incentives (Van Vugt, 2009).

55 In the coastal zone, governance is complex with many organisations and

56 associated institutions designated to manage the system (local, regional, national

57 and international) and many forms of "ownership" models (government, semi-

58 government, public open access, private). To some, the solution to the complex

59 governance situation is to create boundary organisations either through a non-

60 government organisation (NGO) or develop collaborative efforts between

61 scientists and government organisations. Boundary organisations cross the

62 boundary between science and government as a network which draws on both

63 sides to facilitate evidence-based decisions (Guston, 2001). These organisations

64 attempt to solve problems by meeting three criteria, which are: a) creating

65 opportunities and incentives for boundary products, b) facilitating participation

66 of actors from different sides of the boundary and c) establishing or

67 strengthening links between politics and science (amongst others). Boundary

68 organisations are effective, for instance, in the health sector (Drimie and Quinlan,

692011 ) and in waterway management (Abal et al., 2005). 
Whether attempting management with or without these boundary organisations, stakeholder or community engagement is seen as crucial to management success (Dietz et al., 2003; Ostrom, 2009; Van Vugt, 2009). Similarly, the scale of management should include local input into regional management rather than only distant high level and scale management (Ostrom, 2009). Stakeholder engagement has been successfully applied in many single use applications such as fisheries. Often engagement has been established through technical and management boundary organisation (Smith et al., 1999) or various forms of devolved management such as through Territorial User Rights (Chandra, 2011), community based special marine protected areas (Ma et al., 2013) or self management in fisheries (Townsend et al., 2008). However, moving from stakeholder engagement to community engagement has generally not been undertaken as many scholars have presumed that these resource users could not self organise nor be representative (Cox et al., 2011). In this review by Cox et al. (2011) of "self-organised regimes", their findings supported Ostrom's (2009) eight design principles of local stable common pool resource management, which includes well defined boundaries, institutions that are adapted to local conditions, participatory decision-making processes, effective monitoring, scaled sanctions for those who violate rules, mechanisms for conflict resolution, recognition of community self-determination by higher-level authorities, and nested enterprises for large common pool resources.

\subsection{Study area}

The Great Barrier Reef World Heritage Area (GBRWHA) includes the world's largest coral reef system, the Great Barrier Reef (GBR), stretching over 2,300 km 
94 of the coastline of Queensland, Australia (Fig. 1). The Australian

95 Commonwealth's Great Barrier Reef Marine Park Authority (GBRMPA) manages

96 much of the reef. Although GBRMPA manages the biodiversity assets and most

97 activities therein, fisheries and much of the coastal zone inshore of $3 \mathrm{~nm}$ are

98 managed by various other agencies such as the Queensland State Department of

99 Agriculture and Fisheries (DAF), and local councils. There is growing interest and

100 success in engaging local coastal communities to achieve reef management goals.

101 NGOs have played a key role through engaging especially with the farming

102 community to minimise the effects of agricultural runoff (sediments, nutrients

103 and pesticides) (http://reefcatchments.com.au/). Although these NGOs are in

104 many aspects boundary organisations, they have until recently only

105 concentrated on a few impacts areas.

106 The communities who live in the coastal zone of the GBR value the GBR highly

107 (Marshall et al., 2013) and as such there is a significant desire to be involved in

108 local management. It is generally understood by managers that a) it is difficult to

109 regulate all impacts that affect the GBR coast and reef so stakeholder support is

110 essential, and b) given the size of the area and its complexity, it is not possible to

111 have both regional and local knowledge without local input. 


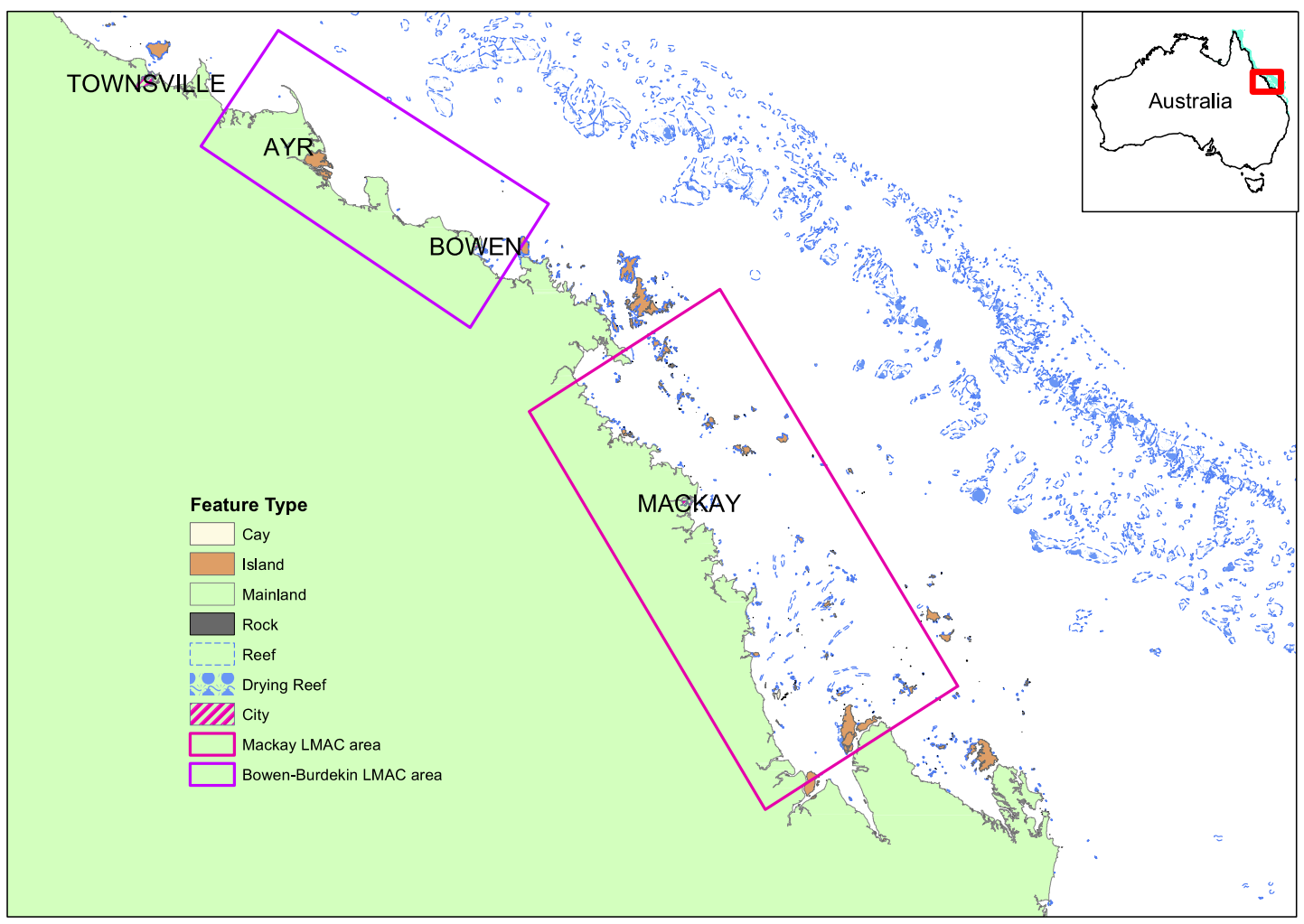

113 Fig. 1: Location of the two case studies shown in the context of the Great Barrier Reef in Queensland,

114 Australia. Inset Map of Australia showing the Great Barrier Reef region (shaded) and the study

115 region (box outline).

116 In a perfect world, high values attributed by a community to an area would

117 generate voluntary compliance and regulation. However, the challenge remains

118 on how to include community input in determining objectives for marine

119 biodiversity and fisheries productivity and effectively link these objectives to

120 decisions made by multiple management authorities, and to do this in a safe and

121 cooperative manner. In an increasingly connected community in Queensland,

122 social media has become a progressively useful medium to focus public opinion

123 (for example the 2014 GetUp campaign against a port development -

124 https://www.getup.org.au/campaigns/great-barrier-reef--3/protect-our-

125 reef/protect-our-reef). However, these forums are seen as not engaging science,

126 management and community in a non-adversarial long-term framework as 
127 described in Cox et al. (2011). There are several case studies and suggestions of

128 what constitutes successful engagement. For example, a successful case study

129 (reviewed by Vural-Arslan and Cahantimur (2011)) in Turkey showed that that

130 community intelligence could be influential to the decision making process.

131 However, there are practical considerations when engaging the community over

132 a longer timeframe, including scheduling and other time commitments. Many

133 emphasise the importance of gaining trust and respect (Vural-Arslan and

134 Cahantimur, 2011), and provide models of engagement (Rowbottom and Bueno,

1352009 ) and move beyond simple models of socio-ecological systems and the

136 perception that most resource users are the same (the "panacea") (Ostrom et al., 137 2007).

138 4. Method

140 Two coastal regions within the GBRWHA area were chosen as case studies.

141 Mackay was chosen as it represented a growing city of about 167,000 people

142 (Australian Bureau of Statistics, 2013) and a large associated Fly-In and Fly-Out

143 (FIFO) community servicing the local mining industry (Fig. 1). It also has an

144 active port, Hay Point, just south of Mackay with the main export being coal.

145 Another major economic driver and employer in the region is sugar cane, where

146 the cane is locally grown and refined into sugar. In terms of natural assets it has

147 national parks, many beaches, offshore islands, inshore and offshore reefs that

148 are part of the GBR. The environment is tropical with the marine environment

149 characterised by very large tidal ranges, key habitats such as mangroves and 

seagrass, and threatened, endangered and protected (TEP) species groups such

151 as dugongs, turtles and inshore dolphins.

152 In contrast, for the second case study the Bowen-Burdekin Shire has a

153 population of about 26,000 people (Australian Bureau of Statistics, 2013) and is 154 approximately $60 \mathrm{~km}$ south of a major city Townsville (and about $350 \mathrm{~km}$ north 155 of Mackay) with Ayr and Home Hill as its main towns (Fig. 1). It is a region 156 characterised as being mainly rural with sugar cane farming as the major source 157 of economic development and employment.

158 These two case studies were chosen for what they have in common while 159 recognising their differences. Both case studies are in rural areas where farming 160 is very important for the areas' wealth generation and employment. A lot of 161 management effort has gone into reducing the amount of sediment, nutrient and 162 pesticide runoff to the GBR in both case study areas. However, the two regions' 163 ports are distinct in size and activity and importantly in terms of active 164 development and extension proposals. During the study period, a major port 165 upgrade in the Abbott Point area (just south of Burdekin), with associated 166 dredging, was proposed. This port upgrade was a source of conflict in the local 167 region and also created great controversy in wider Australia. Whereas the 168 Mackay port was well established with no upgrades happening at the time this 169 research was undertaken and therefore activities in the Mackay port was not as 170 controversial as the Abbott Point development. The population size was also 171 very different with Mackay having a far larger urban footprint with a growing 172 city although this may have slowed down in recent years due to the general 173 downturn in mining activity. 
175 A hierarchical system of engagement was attempted in both regions. At the

176 highest level, a community group, the Local Marine Advisory Committee (LMAC)

177 run by GBRMPA was already established in each of the regions; although the one

178 in the Bowen-Burdekin was more recently established than the one in Mackay.

179 Their charters are to advise GBRMPA on local management issues

180 (http://www.gbrmpa.gov.au/about-us/local-marine-advisory-committees).

181 Although the chair is elected and paid a nominal fee, the members are volunteers

182 sourced from the community. LMACs have a 3-year term and calls for

183 nominations are made normally to stakeholder groups, although a nominee can

184 be independent. There is some vetting based on experiences GBRMPA (or a

185 referee) has had with individuals and their ability to contribute constructively.

186 Membership of the LMACs in our case studies included representatives from

187 GRBMPA, cane growers, commercial and recreational fishers, and local Port and

188 Council employees. The LMACs aim is to achieve a balanced representation,

189 although this is not always achieved. The quality of participation and 'team'

190 output can be highly variable.

191 Since the LMACs met every quarter with a full agenda, a sub-committee was

192 formed and called the LMAC Reference Group (RG). This was made up of LMAC

193 members who volunteered for the group and additional members (i.e. people

194 who were previously on the LMAC) that would cover a broader skill set. The

195 project lead facilitated the RG meetings, with a member elected as the RG chair.

196 In addition to the project team, who facilitated and attended the RG meetings,

197 "managers" (defined as people that either directly or indirectly influence 
management decisions) from DAF and GBRMPA, and social, economic, mathematical and environmental scientists from State and Commonwealth

200 agencies participated in the RG meetings.

201 Within a few months of project engagement in the Bowen-Burdekin area,

202 historical and present issues (such as the Abbott Point port development

203 controversy; members of the LMAC being stretched over two distinct regions

204 meaning members often had to travel long distances to attend meetings,

205 previous poor engagement processes) meant that participation was minimal. An

206 alternative approach was undertaken described in detail in Dichmont et al.

207 (2014), but generally it meant the project team engaged with individuals directly

208 and separately instead of in a group. Outside this one-to-one engagement

209 interactions between the different RG and LMAC members were minimal. In

210 Mackay, the RG was very successful and there was engagement with this group

211 throughout the process. However, the indigenous member resigned from the

212 group due to circumstances external to the RG.

213 At various stages in the process (described further below) community and senior

214 level managers' input was sought. All documentation was kept in a traceable

215 format, i.e. iterations of all steps could be traced through the various meetings to

216 its original source.

217 A local Mackay GBRMPA person devoted an enormous amount of time on

218 support and engagement in-between meetings. This support was essential and

219 provided local continuity.

220 A sequence of steps were undertaken - see Dichmont et al. (2014) for more

221 details. Steps 3 to 12 were undertaken in the Mackay case study only: 
1. Qualitative modelling (Dambacher et al., 2003; Dambacher and RamosJiliberto, 2007) of the Mackay coastal system was carried out (Dichmont et al., 2014) (both case studies). The RG was asked to list assets of importance to them in the region and identify the impacts on these assets. They were then asked to select their priority asset for which the impacts and feedback were modelled in more details. An introduction on (see Dichmont et al. (2014));

2. A review of existing objectives from government organisations, NGOs and Natural Resource Management (NRM) bodies that were directly or indirectly relevant to the region was undertaken (both case studies). This was then combined into a hierarchical tree format using input from a series of workshops attended by the RG and LMAC (Dichmont et al., 2014; Van Putten et al., 2015). After this stage, the Bowen-Burdekin case study was discontinued given the controversy around the Port development and its overwhelming impact on the issues being discussed.

3. A survey of the RG, LMAC and Mackay public was undertaken to ascertain the relative importance of different objectives. Dichmont et al. (2014) describe the analysis details and survey methods in detail but two approaches were undertaken - the recommended Analytical Hierarchical Process (Pascoe et al., 2013; Saaty, 1980) and a new Point Allocation method at each level of the objective tree and called the Hierarchical Point Allocation method (Dichmont et al., 2014). The survey form is provided for illustration in Supplementary Material (SM) Section 1; 
4. Managers gave presentations to the RG about existing management actions that were being undertaken in the Mackay coastal zone so that they could subsequently discuss any remaining management actions that needed to be addressed for the different assets;

5. Topics relevant to the focal question of management of biodiversity and fisheries in the coastal zone were developed in session (see SM Section 2). These described both key assets (such as mangroves and seagrass) and key issues (such as development).

6. Over a period of just over 12 months, the RG undertook a series of workshops that discussed management options for these topics. Each workshop included:

a. Presentation by an expert of background information pertinent to Mackay about the specific topic being discussed at the workshop;

b. The RG, project team and invited expert workshopped an issues register, direct and indirect management options, and responsible agencies for each issue (Dichmont et al., 2014) (see SM Section 2). The discussions were held either in small groups or as a whole group, depending on the number of workshop participants. Direct management options were defined as a management action that is undertaken directly by the agency responsible for managing the issue and could include proposing legislative changes, whereas indirect management options were those that could have the same impact as the direct option, but undertaken indirectly through a non-responsible agency or the community. Issues or management options could be geo-located using a Google $\mathrm{e}^{\mathrm{TM}}$ map of the study 
region. Relevant qualitative models were also made available to assist with highlighting past discussions on the relationships within the system on that topic.

c. Initially, the issues list was developed separately from the management actions, but this was seen as inefficient. The meeting length was increased from a couple of hours to half a day and all aspects of a topic (i.e. issues and actions) were covered together as described above.

d. The topic sequence was generally down the catchment (i.e. geographically in direction of flow from source to river mouth and then into near-shore domain), but most of the contentious topics (port and urban development, fisheries) were addressed as the last topic. were subsequently modified during two workshops. In order to articulate the pathway of combining management options, the project team used the well-known United Nations Environment Program risk assessment framework known as DPSIR (Drivers, Pressures, States, Impacts and Response) (Pirrone et al., 2005; Smeets and Weterings, 1999). A more simplified form of Pressure-State-Response -was ultimately used. The results were presented with an associated storyline for each Management Strategy that provided background and a list of the relevant management options (see example SM Section 4). 
8. An impact assessment was undertaken in two phases (with the analysis method described in Dichmont et al. (2014):

a. The RG was asked to rate each management strategy from -3 ("considerably worse than current situation") to +3 ("considerably better than current situation") against the low level objectives.

b. They were also asked to score their level of confidence in their ability to answer question a) for each objective from a score of 1 ("very unsure") to 5 ("certain").

c. A subsequent workshop was then held where the RG, Mackay coastal managers and NRMs were asked to undertake the same impact assessment scoring. However, due to time constraints scores were made during the meeting against the high level goals only (although well-being was split into social and economic goals).

9. The overall priority list and final set of management strategies (SM Section 3) were provided to the RG for comment, and thereafter to the management workshop.

10. Storylines in the form of report cards were developed that described the management strategies and actions for use by RG and LMAC members. These were made available online for the community.

11. Letters to the two management agencies most affected were also written, but drafted in language more appropriate for this target audience. 12. All documentation was always approved by RG members before release. 
318 A review of the successes and failures of the two case studies by the project team

319 were undertaken through questionnaires to the Mackay RG and managers. A

320 final framework was developed for future engagement.

\section{5. Results and Discussion}

\subsection{Comparing the case studies}

323 The progress of the different case studies was heavily impacted by external

324 factors, in the case of Bowen-Burdekin a contentious port development proposal

325 and previous unsuccessful engagement processes, amongst others. The Bowen-

326 Burdekin LMAC was also split over two reasonably different regions and was

327 also the newest formed committee of the LMACs. This case study also did not

328 have a local GBRMPA member (as opposed to the Mackay case), which helped

329 build trust and continuity. The level of distrust and at times acrimony divided the

330 volunteers from the Bowen-Burdekin RG and LMAC such that the engagement

331 process was not completed in this case study. In that context, however, it was

332 still possible to complete the objective review and hierarchy through individual

333 or smaller group interactions that produced a useful product (Van Putten et al.,

334 2015). In contrast, the RG in Mackay was highly functional and delivered more

335 than 150 hours of volunteer time (not including the project team time). Given the

336 time and energy they put in, ownership of the output by the Mackay RG

337 increased over time with members controlling the final product (in terms of both

338 content and detailed wording). This was not the case in the Bowen-Burdekin

339 where the project team was more influential on the final product. However, 
340 despite these differences in approach the final objective trees from each case

341 study were quite similar which allowed generic objectives to be developed.

342 A further issue in the Bowen-Burdekin case study was stakeholder fatigue.

343 Previous studies had used several of the members for other strategy discussions

344 especially on fisheries. There had been significant progress in developing

345 regional management strategies for the Burdekin area, with genuine interest and

346 support by the then Minister for Fisheries, but which failed to be progressed

347 because of poor overall project management and poor communication of the

348 objectives of the project to the community. Vocal opposition to the project by a

349 particular influential stakeholder group also influenced this outcome, but who

350 were not resident in the area. This meant that some of the members felt the

351 project was repeating previous work and were worried that the end result would

352 be the same. The Mackay case demonstrated that the process followed as part of

353 this project could in fact lead to avoiding conflict and that a rigorous semi-

354 quantitative sequential approach contributes to a successful completion and

355 overall outcomes.

356 Interestingly, as the Mackay RG increased in confidence and realised the value of

357 their contribution and increased knowledge due to access to experts, the link

358 between the RG and LMAC became more tenuous. RG members expressed their

359 frustration with the LMAC and developed a perception that they only discussed

360 small-scale issues compared to RG discussion.

361 Aspects that contributed most to the successes in Mackay were that:

362 - There were a large number of highly dedicated local volunteers within the

363 local community, scientific community, and amongst the managers. 
- The scientific input was of an excellent standard with well-pitched presentations due to verbal or written communications indicating what was required provided beforehand. These presentations were very motivational to RG members who indicted they valued them and that they influenced the way they understood both management and biophysical processes. dedication to provide mostly local content. In addition RG members (and managers) also gained immense local knowledge through visits to local examples of good and bad management practices.

- Of key importance in terms of generating interest and knowledge was the

There were strong links established between managers and RG members. Discussions about contentious issues occurred, but debates over these occurred in a climate of mutual respect and understanding. However, senior management support for the uptake of the final management strategies was variable. Lack of uptake of the final outcome by some agencies were because:

- The RG had no broad official mandate to represent Mackay, as they were not elected, which makes management action perceived as being more risky.

- There was basic resistance on behalf of management to change and lack of enthusiasm to undertake the effort that would be required to effect any change. This is related to the conundrum that as part of the project the managers needed to be open and or empathetic to community input (as presented through the RG) despite this input being given by a community 
group that by nature was not representative of a large region. This meant that there was a perception that it would be difficult or less attractive to act on the basis of their advice.

- Managers' perception of what was happening on the ground was considerably different from that of the RG. This was due to a mixture of managers not being aware of local issues and RG members not being aware of what work management agencies were, or were not, undertaking.

- The final management strategies were seen as "wishy-washy" and not radical, and also managers perceived that many of the strategies had already been implemented. However, this again highlighted differences in manager's perception about what had been implemented and what had actually happened on the ground as understood by the RG. Evidence of bad and good practices and of the discrepancy between management decisions and on-ground actions was shown to the project team and to some of the managers. These demonstrated that manager's perception that issues had already been addressed was not always borne out by the evidence and therefore their developed management strategies still had

407 The process followed was accepted as comprehensive, but required significant

408 volunteer input. Some of this time commitment was due to the test case nature of 409 the work where several approaches were trialled by RG members. A shorter, less 410 time consuming version is suggested below as a refinement based on the

411 outcomes of our work. 
413 The qualitative modelling was used as an introduction for the members to

414 discuss their present knowledge of the area, for their views were valued and to

415 inform the project team on key issues that needed to be addressed and which

416 assets needed to be protected. Although the project team provided the

417 qualitative models to the RG at the time of management strategy development,

418 the RG members did not use the models. Since the process of qualitative model

419 development is quite extensive - in this case partly due to the fact that different

420 methods were trialled - and because the models were not used later in the

421 process, this step could be removed from the process. Alternatively it could be

422 enhanced, or further value could be added to the models, by developing them

423 into Bayesian Belief Networks (Hosack et al., 2008). This enhanced approach

424 may be more useful to developing management strategies and the additional

425 effort thus beneficial.

426 Undertaking the objective development process before discussing management

427 options was essential to encourage group cohesion and trust. This sequence of

428 events was based on the adaptive management loop (Sainsbury et al., 2000;

429 Walters and Hilborn, 1976), where objectives are defined so that management

430 strategies can be contextualised and actions can be reviewed once they are

431 implemented. Conflict is reduced because all objectives can be included in the

432 objectives setting process (i.e. there is no need to exclude any specific objective).

433 In addition, each participants' individual weightings are preserved in the

434 objectives scoring process giving each participant a sense that their opinions are

435 considered and important. In summary, at this early stage of the process, the 
436 group is new and trust has yet to be developed. The objective stage does not

437 need consensus or agreement as a person can down weight an objective they

438 disagree with and highlight those they feel are most important. For this reason,

439 undertaking the objective process first builds trust. Conflicts are diffused and

440 informal feedback from the group indicated that generally participants found

441 this aspect interesting and unique, particularly given that their past experiences

442 mostly bypassed this part and instead moved straight to the management

443 strategies.

444 The objective review was surprisingly quick and easy (given that most of the

445 agencies had a strong online presence and documents were therefore easily

446 obtainable). In addition, the process followed with the Mackay RG to develop the

447 hierarchy led to increased group cohesion and the process was generally

448 enjoyed. However, a successful review was also achieved in the other case study

449 site through a more individual approach although perhaps with not as much

450 attachment to the final product.

451 Several approaches were trialled when developing the management strategies

452 with the RG in Mackay. Group input in the process highlighted that discussing the

453 each asset in conjunction with the issues that pertain to as one topic, and

454 covering only one topic per meeting, worked best. At each meeting, access to an

455 expert with local knowledge on each topic was essential. Undertaking the 'Issues

456 Register', and listing direct and indirect management options at the same time

457 was the most productive and produced a more cohesive product.

458 The sequence by which topics were discussed roughly reflected a progression

459 from the top of the catchment, down along the catchment to the ocean. This 
460 sequence made intuitive sense, reduced overlap and highlighted the connectivity

461 of the system. The most controversial topics arose at the end of the discussion

462 process (at the bottom of the catchment) and by this stage the group was very

463 familiar with each other's views and therefore more open to opposing proposal

464 for management actions. The motive for undertaking the most controversial

465 topics towards the end is that the investment of the RG by this stage was high

466 thereby reducing the incentive to abandon the process but rather to remain

467 engaged in finding a solution. Members were also aware of the different weights

468 given to the various objectives, so many of the contentious views were already

469 generally known and were often discussed out of session. In other words,

470 members were more prepared to "agree to differ" or accommodate their ideas

471 rather than increase conflict and risk breaking the process, which was now more

472 than a year long. In the Burdekin the group was unable to progress past the

473 objectives stage. In this case study, extant conflict in the community already

474 existed due to past experiences and the controversial Port development. This

475 indicates that existing conflicts may not be easily be resolved by the process

476 proposed in this research, but that the process is better at deferring potential

477 future conflicts as was evident from the Mackay case study.

478 Traceability about where the objectives and management options came from was

479 an essential component that maintained trust between participants and trust in

480 the process. The RG feedback emphasised this point and that they felt their views

481 were listened to through having this transparency.

482 Explicitly making the relative importance of the defined objectives to the whole

483 group helped highlight that there was in fact quite a lot of consistency in the RG's 
view and their attribution of the relative importance for each goal. In session discussion of the results allowed general articulation of RG member's values and opinions in a more factual manner.

487 By embedding managers in the project team and RG was an extremely important component of linking the community with the management system and, as such, was successfully implemented. However, connection to more senior

490 management and leaders in strategic thinking which has been shown to be very

491 influential in other studies, for example Dutra et al. (2014), was weak in our 492 process partly due to the project team's work load and other commitments of the 493 participants and managers. The lack of connection to senior management made it 494 more difficult to get traction (with regard to implementation) at the end of the 495 process. However, senior managers were approached at the early stages of the process and the project team was told to wait until the end when there was more

497 substance. Some of the reason for this was that senior managers wanted to stay

498 at arms length from the process so they could wait to pick and choose options 499 that are possible to implement without having directly or indirectly endorsed 500 them by being involved in the process. As a consequence, the final manager 501 meeting was destructive for some RG members even though the project team 502 warned the RG that some negative response from managers could be expected. 503 As a result, a balance between the RG and managers' needs is required, where 504 more regular contact is made rather than using the manager's approach of 505 'connecting towards the end'. Closing this engagement and timing gap between managers and the RG (highlighted in the Mackay example) throughout the

507 process is a priority. If these gaps were addressed this may assist in solving the 508 conflict in perception such that managers felt much work is already being 
undertaken in some areas whereas the RG believe these were ineffective or

510 absent in the ground actions.

511 Managers suggested the most useful part of the process was the impact

512 assessment. This provided them with a list of relative priorities for each

513 management strategy they could use for funding purposes. It also uncovered a

514 significant gap between what managers thought was a priority and this same

515 perception by the community, in addition to the mismatch in the eyes of the

516 community of the effectiveness (and wisdom) of the management action(s) that

517 addressed the managers perceived priorities.

518 After the managers meeting, the final set of management strategies was

519 separated into products specific to the two major agencies relevant to the coastal

520 zone (fisheries management - DAF and local government arrangements -

521 Regional Council) and these were much more successful in terms of uptake.

522 These included letters to each agency that highlighted the possible management

523 solutions to specific issues highlighted by the RG. These two letters were also

524 promoted behind the scenes by key members of the project team and were

525 worded in the language used in the bureaucratic system of government agencies

526 rather than those of the RG. Both products were needed for the process, as there

527 was a demonstrated disconnect between local and manager's views.

528 Disputes (potential or actual) were resolved with the aid of very clear ethics

529 guidance processes, by the sequence of the stepwise process allowing open and

530 transparent discourse, by the independence of the project team, and imbedding a

531 local in the project team. In Burdekin, adapting the process to one based on an

532 individual rather than workshop format reduced additional conflict in that area 
533 (where conflict was already extant). In Burdekin, the LMAC and other

534 participants agreed to stop half way through. The acceptance that circumstances

535 were too difficult and stopping the process was an important learning outcome

536 that can be drawn from this project. In Mackay, a RG member was the chair but

537 the facilitator was from the project team, which meant that these two were able

538 to control any conflict without compromising the local or the research team.

539 Clear guidance on workshop behaviour has been provided at the start of the

540 process to all participants, and these were consistently adhered to.

\subsection{Generic process}

542 The following describes a generic community engagement process. However, it is

543 not a recipe for engagement, but more a guide that helps outline what is possible.

544 The community engagement process can be simplified into four steps (Fig. 2):

545 i) developing the engagement process;

546 ii) defining objectives (which includes the review of existing objectives, creating

547 the hierarchy and obtaining their relative importance);

548 iii) developing the management strategies (provide information, define issues

549 and develop actions); and

550 iv) setting the priorities through a relative impact assessment.

551 It is recommended that community engagement be conducted following the

552 approach in the Mackay RG but with enhanced LMAC (generically called the

553 Header Group) involvement where the header group gives direction by defining

554 the RGs tasks and timelines (Fig. 3). The header group should meet less

555 frequently than the RG. Managers should be embedded in the RG. The header 
556 group should preferably have some authority and representativeness, whereas

557 the RG membership should maintain some representation but mainly consists of

558 volunteers willing to generously provide their time. Important influencers

559 should be identified at an early stage in the process so that they can be included

560 in the discussions as much as possible. The RG chair should be elected from the

561 RG membership but facilitation should be provided by the project team to allow

562 all RG members equal access to the discussion, but also for the chair to be able to

563 contribute to the discussion. A local person that is a member of the project team

564 is a huge advantage as this person can be a conduit for out of session

565 conversations.

566

1. DEVELOP ENGAGEMENT APPROACH

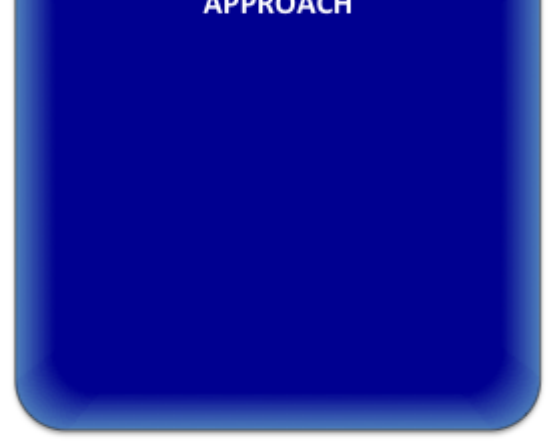

\section{SET PRIORITIES}

- Relative impact assessment

\section{7}

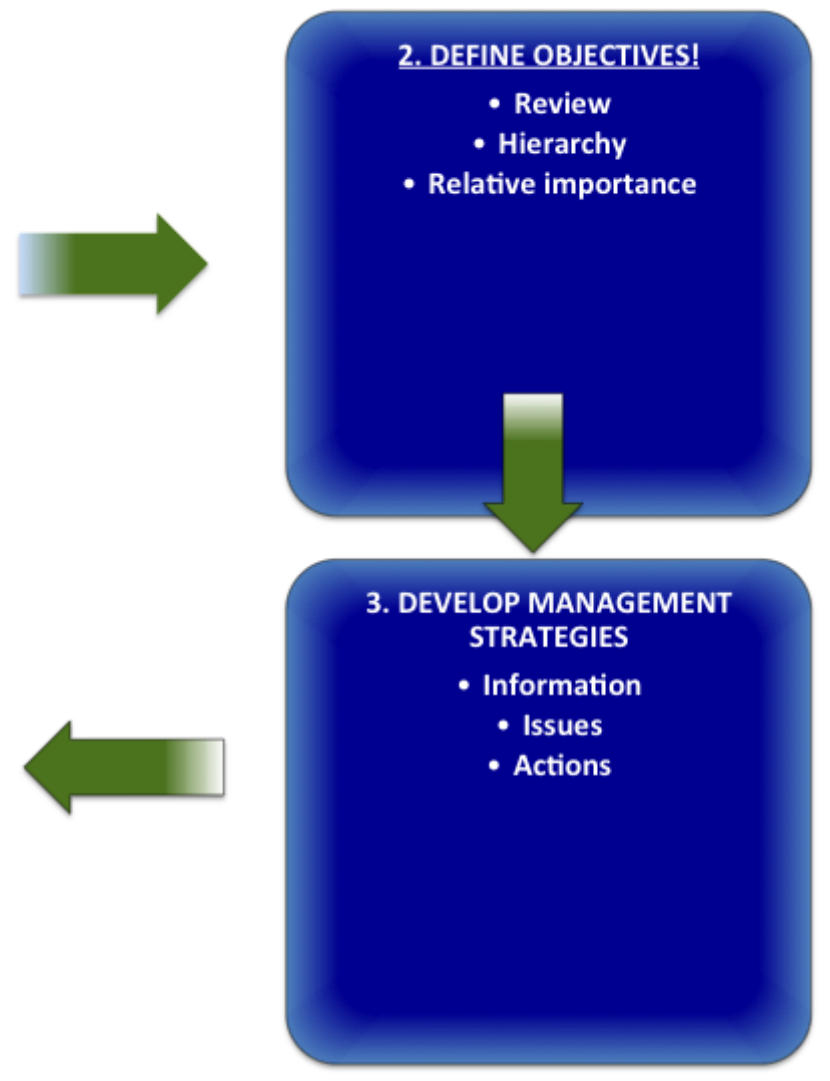

Fig. 2: Generic process of developing management strategies using local community input 


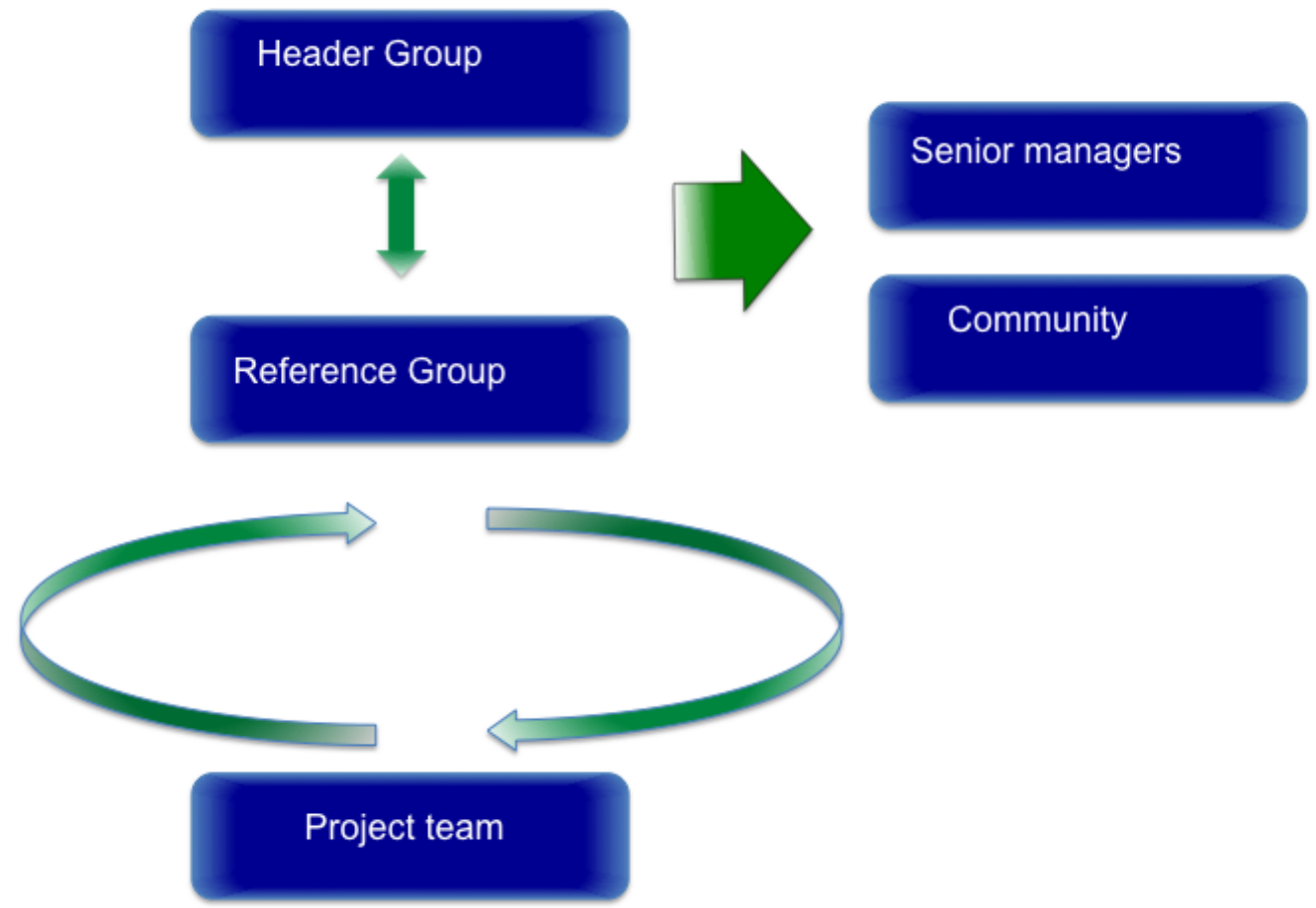

571 Fig. 3: Generic engagement process

573 A very important aspect of building trust is for the objectives review to maintain

574 links to source documents and also to keep track of versions when the RG and

575 Header Group input is obtained. If there is a need to speed up the process, a

576 generic objective tree to develop management strategies for coastal zone

577 fisheries and biodiversity can be used and the lower level (the objectives) can be 578 subsequently added for more local content (Fig. 4). 


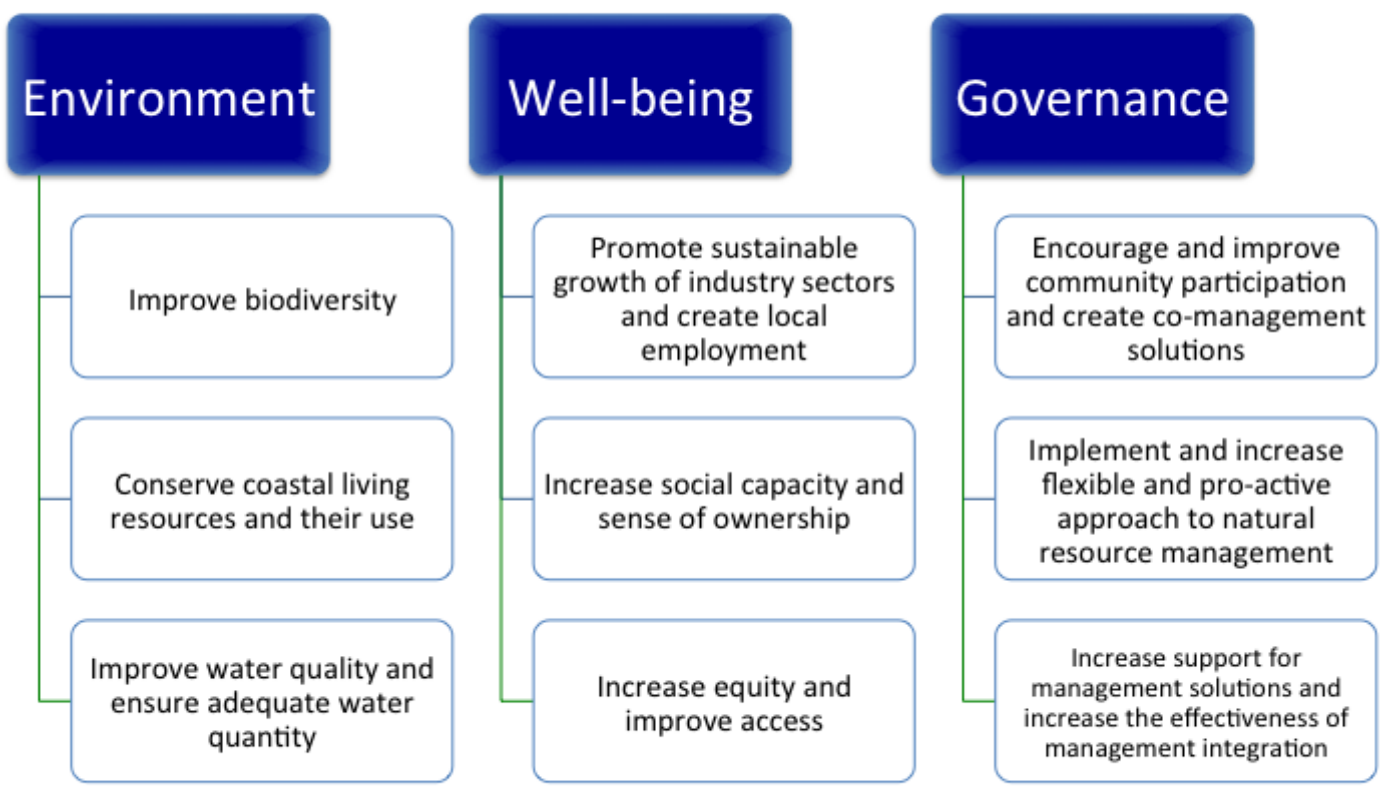

$580 \quad$ Fig. 4: Generic objectives hierarchy for the management of the coastal zone fisheries and

581 biodiversity (Van Putten et al., 2015).

582 Determining the objective relative weighting can be kept within the Header

583 Group and RG (rather than going to the community as well), as this data will be

584 used when the management strategies are created by the Header Group and RG.

585 Obtaining objectives weightings from the community is time consuming.

586 However, if a community survey is part of the project plan can be obtained,

587 doing local radio interviews in which the link to online surveys is publicised

588 seems to work well in obtaining participation (Dichmont et al., 2014). A paper

589 backup survey available from a local office is also needed for those people who

590 wish to participate but are not able to access the internet. There should be a

591 preference for the simplest cognitive method to obtaining relative objective

592 weightings. More confusing and controversial approaches such as the Analytical 
593 Hierarchical Process as described in Dichmont et al. (2014) should be used only

594 in appropriate circumstances. An example of the simple survey using the generic

595 objectives approach is provided (Supplementary materials Section 1).

596 To ensure that the existing management situation can be adequately described

597 before the management strategies are fleshed out, it is suggested that this part of

598 the process starts with a meeting between managers and the RG and Header

599 Group in which existing management measures are comprehensively described.

600 The management strategy question should be divided into topics that combine

601 key assets and with the relevant issues that pertain to them. The topic sequence

602 should allow for connectivity in the system to be highlighted but controversial

603 topics should be raised toward the end of the process when trust and awareness

604 have already been established. For each topic, an expert with local knowledge on

605 that topic should attend. Using the simpler Pressure-State-Response framework

606 (Fig. 5) - the precursor to the Driver-Pressure-State-Impact-Response approach

607 (Pirrone et al., 2005; Smeets and Weterings, 1999) - an issues register can be

608 developed with direct and indirect management actions (Table 1). Some

609 flexibility on the day is needed in terms of whether discussions are made in small

610 groups or the whole. The project team should collate these using a database and

611 provide these to the RG for input. The Header Group should support the final

612 product. 


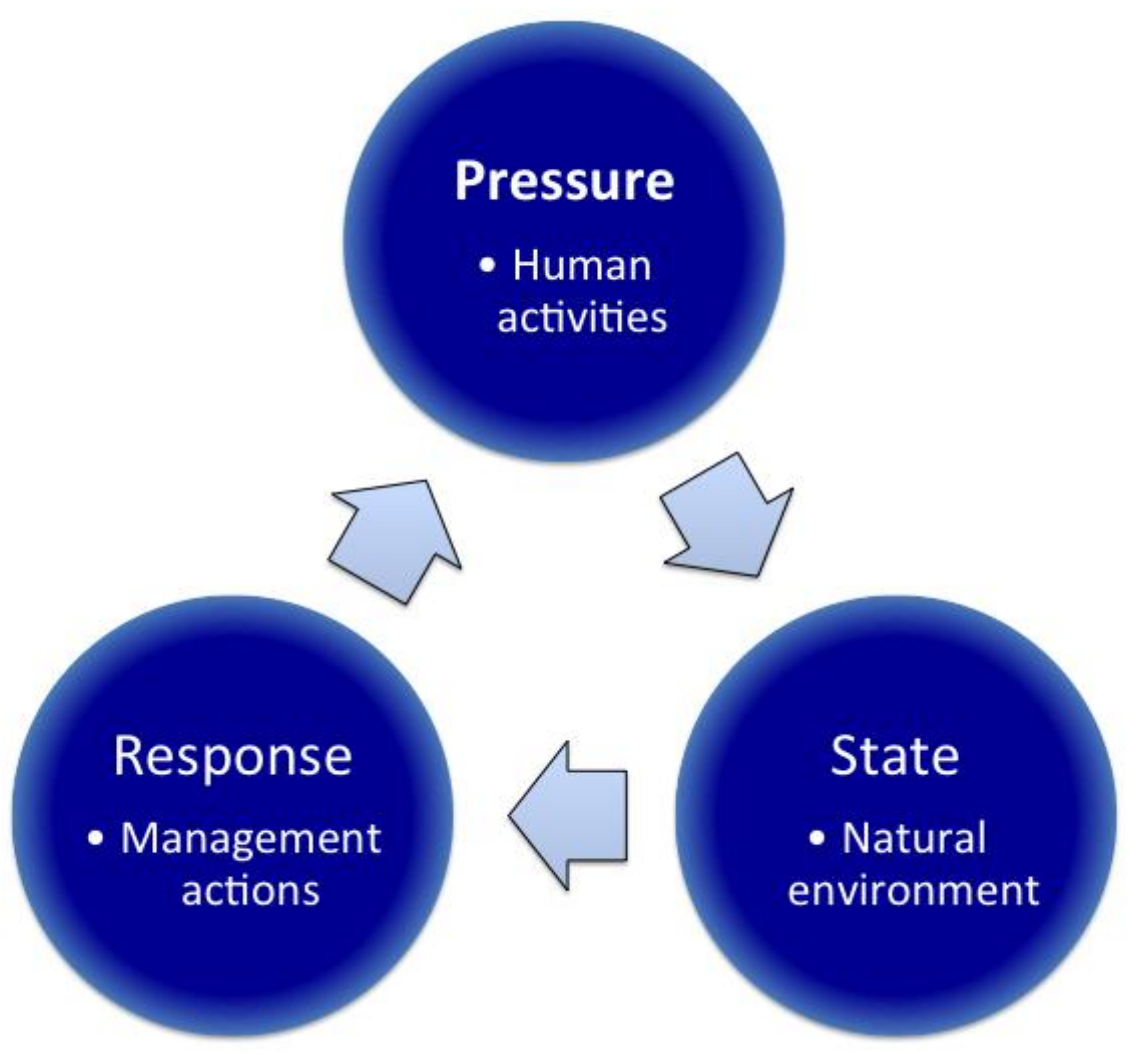

614 Fig. 5: A drawing that could be provided to explain the Pressure-State-Response framework

\begin{tabular}{|lll|}
\hline Topic & & \\
\hline Issue & Direct management action & Indirect management action \\
\hline Issue 1 & Action 1a & Action 1b \\
\hline Issue 2 & Action 2a & Action 2b \\
& Action 3a & Action 3b \\
\hline
\end{tabular}

618 Given the time usually available, particularly to senior managers, the impact

619 assessment should be undertaken for the highest level objectives by both the RG

620 and the Header Group prior to the key managers meeting. It can be repeated in 
621 session at the managers meeting to obtain information on influence - see

622 example tables in Dichmont et al. (2014). Undertaking the impact assessment at

623 these two separate meetings highlights relative priorities and the difference

624 between managers and RG members. The analysis method is provided in

625 Dichmont et al. (2013) and Dichmont et al. (2014).

626 At least one managers meeting between senior managers, embedded managers,

627 the Header Group and RG should be undertaken. In order to increase the chance

628 of implementation, it is likely that follow up meetings with managers are

629 essential and documents specific to their needs and communication style will

630 need to be produced.

631 A generic strategy communication tool (Fig. 6) can be used for each of the

632 different management strategies to ensure that all bases are covered. All

633 management actions can be the result of either direct actions on individual

634 impacts, such as reducing littering and runoff from farms and development

635 (outer ring at top), or responses by means of resource management, added

636 compliance, and basic research (inner top semi-circle). Coordinated educational

637 campaigns targeted at the local community, industries and government agencies

638 (bottom ring) are a key action that can help influence positive behaviour and

639 attitudes towards inshore resources. The final outcomes expected from the

640 management strategies are:

641 1. Healthy communities and natural environment

642 2. Integrated and inclusive management

$643 \quad 3 . \quad$ Profitable local industries 


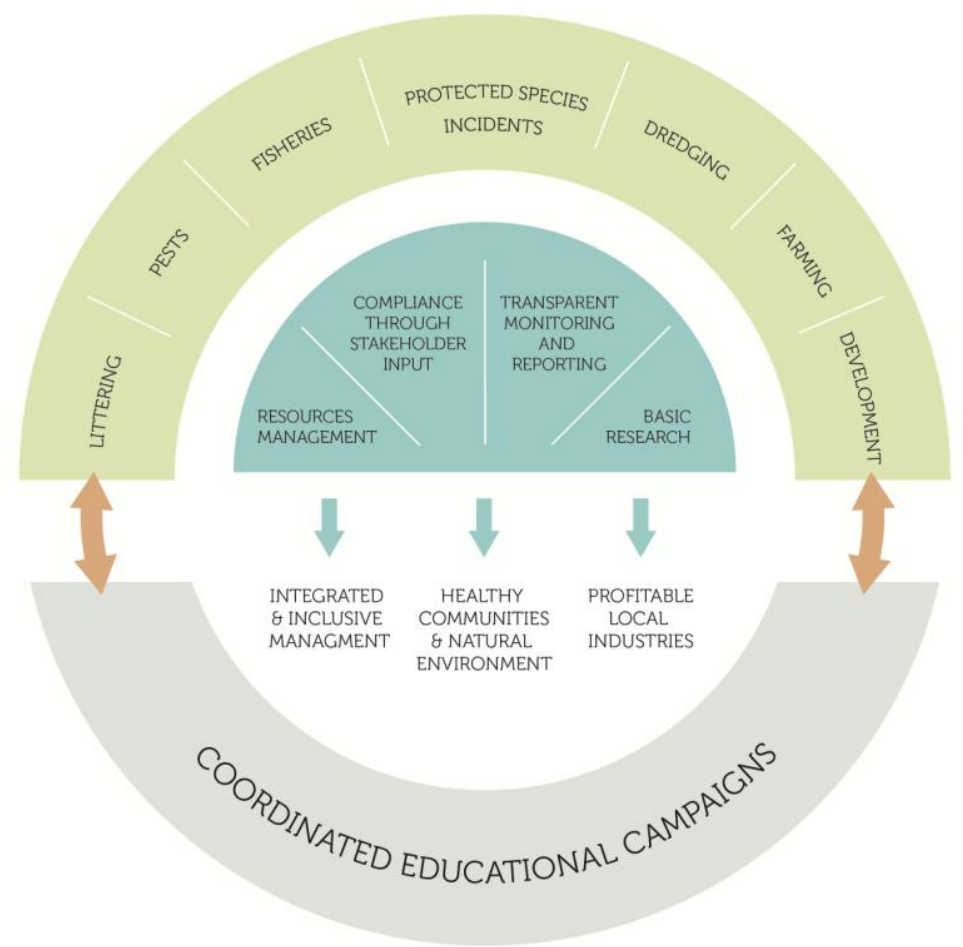

644

645 Fig. 6: Generic classes of management strategies as a communication tool with which to explain the

646 management strategies. Graphic design: Dr Manuela B. Taboada, Queensland University of

647 Technology

648 A clear ethics approval process that includes the stage at which further

649 engagement with communities or an individual member of the group is deemed

650 as potentially damaging is important. The steps described in the ethics

651 application used for this research was in fact used for one of the two case studies

652 where engagement was discontinued. A flexible approach is therefore still

653 important to keep in mind, as each situation is likely to bring its own

654 idiosyncrasies.

655 6. Conclusions

656 A generic approach to developing management strategies based on two case

657 studies is outlined. The case study experience highlights that embedding 

leaders should be part of the process from the start rather than coming in only at the end at which time a more tangible but less controversial product is available.

663 Continuous engagement by senior managers and thought leaders is important

664 because failure is most likely to occur at the implementation phase. Throughout

665 the process steps are needed to ensure reduced risk of conflict. The most

666 important step in risk reduction is to discuss objectives prior to management

667 strategies. This allows the group to value and understand each other's

668 perspective. The gap between the perception of managers that their

669 management actions are in place and outcomes are achieved, and the

670 community's perception of the effectiveness of the same actions needs to be at

671 least narrowed but preferably closed. This is particularly important as the

672 significant volunteer time required to support the process evident in this project,

673 showed the wish for local scientists and community members to be part of

674 regional management.

\section{7. Acknowledgements}

676 This work would not have been possible without the incredible input from the

677 Mackay and Bowen-Burdekin community, and their associated LMAC members.

678 Most notably, those that helped us tirelessly in Mackay as members of the

679 Mackay LMAC RG. We developed a survey in Mackay to gauge residents' opinions

680 of what mattered to them with regard to coastal management, and more than

681140 completed what was a taxing survey. These respondents also helped recruit 
682

683

684

685

686

687

688

689

690

691

692

693

694

695

696

697

698

699

700

701

702

703

704

705

706

other survey participants. Some of the participants attended in-person sessions held in Mackay and stayed to give us robust advice on the survey design. These comments were instrumental when developing a new method. Special mention must be made of Carolyn Thompson, GBRMPA, Mackay - her involvement and tireless work was probably the most significant factor allowing us to get real traction in Mackay.

We thank the CSIRO and external reviewers of the paper and Dr Manuela B.

Taboada for graphic design of Figure 6.

This research was funded by the Department of Environment; the

Commonwealth Scientific and Industrial Research Organisation; the Queensland

State Department of Agriculture Fisheries and Forestry; the Great Barrier Reef

Marine Park Authority; the Queensland State Department of Environment, Heritage and Protection; and James Cook University.

\section{References}

Abal, E.G., Dennison, W.C., Bunn, S.E., 2005. Healthy waterways healthy catchments: making the connection in South East Queensland, Australia. Moreton Bay Waterways and Catchment Partnership, Brisbane, p. 222. Australian Bureau of Statistics, 2013. State and territory statistical indicators., Technical Report 1367.0. Australian Bureau of Statistics.

$$
\text { Chandra, A., 2011. A Deliberate Inclusive Policy (DIP) Approach for Coastal }
$$

Resources Governance: A Fijian Perspective. Coastal Management 39, 175-197.

Cox, M., Arnold, G., Tomás, S.V., 2011. A Review of Design Principles for

Community-based Natural Resource Management. Ecology and Society 15, 38.

Dambacher, J.M., Luh, H.K., Li, H.W., Rossignol, P.A., 2003. Qualitative stability and ambiguity in model ecosystems. American Naturalist 161, 876-888. 
Dambacher, J.M., Ramos-Jiliberto, R., 2007. Understanding and predicting effects of modified interactions through a qualitative analysis of community structure.

709 Quarterly Review of Biology 82, 227-250.

710 Dichmont, C.M., Dutra, L.X.C., van Putten, I., Deng, R.A., Owens, R., Jebreen, E., 711 Thompson, C., Pascual, R., Warne, M.S.J., Quinn, R., Thébaud, O., Bennett , J., Read, 712 M., Wachenfeld, D., Davies, J., Garland, A., Dunning, M., Waycott, M., Collier, C., J.,

713 D., Playford, J., Harm, R., Gribble, N., Pitcher, R., 2014. Design and implementation 714 of Management Strategy Evaluation for the Great Barrier Reef inshore (MSE715 GBR). Report to the National Environmental Research Program, and Reef and 716 Rainforest Research Centre Limited Cairns, pp. 284 pp.

717 http://www.nerptropical.edu.au/publication/project-292-final-report-design-

718 and-implementation-management-strategy-evaluation-great.

719 Dichmont, C.M., Pascoe, S., Jebreen, E., Pears, R., Brooks, K., Perez, P., 2013.

720 Choosing a fishery's governance structure using data poor methods. Marine 721 Policy $37,123-131$.

722 Dietz, T., Ostrom, E., Stern, P.C., 2003. The struggle to govern the commons. 723 Science 302, 1907-1912.

724 Drimie, S., Quinlan, T., 2011. Playing the role of a 'boundary organisation': getting 725 smarter with networking. Health research policy and systems / BioMed Central 9 726 Suppl 1, S11.

727 Dutra, L.X., Ellis, N., Perez, P., Dichmont, C.M., de la Mare, W., Boschetti, F., 2014. 728 Drivers influencing adaptive management: a retrospective evaluation of water 729 quality decisions in South East Queensland, Australia. Ambio 43, 1069-1081.

730 Guston, D.H., 2001. Boundary Organizations in Environmental Policy and 731 Science: An Introduction. Special Issue: Boundary Organizations in 732 Environmental Policy and Science (Autumn, 2001) 26, 399-408.

733 Halpern, B.S., Kappel, C.V., Selkoe, K.A., Micheli, F., Ebert, C.M., Kontgis, C., Crain, 734 C.M., Martone, R.G., Shearer, C., Teck, S.J., 2009. Mapping cumulative human 735 impacts to California Current marine ecosystems. Conservation Letters 2, 138736148.

737 Hosack, G.R., Hayes, K.R., Dambacher, J.M., 2008. Assessing model structure 738 uncertainty through an analysis of system feedback and bayesian networks.

739 Ecological Applications 18, 1070-1082. 
740 Kroon, F., Turner, R.E., Smith, R., Warne, M., Hunter, H., Bartley, R., Wilkinson, S.,

741 Lewis, S., Waters, D., Caroll, C., 2013. Sources of sediment, nutrients, pesticides

742 and other pollutants in the Great Barrier Reef catchment. Queensland State

743 Government, Reef Water Quality Protection Plan Secretariat, Brisbane.

744 Ludwig, D., 2001. The era of management is over. Ecosystems 4, 758-764.

745 Ma, C., Zhang, X., Chen, W., Zhang, G., Duan, H., Ju, M., Li, H., Yang, Z., 2013. China's

746 special marine protected area policy: Trade-off between economic development

747 and marine conservation. Ocean \& Coastal Management 76, 1-11.

748 Marshall, N.A., Bohensky, E., Curnock, M., Goldberg, J., Gooch, M., Pert, P., Scherl,

749 L., Stone-Jovicich, S., Tobin, R.C., 2013. A Social and Economic Long Term

750 Monitoring Program for the Great Barrier Reef. Key Findings 2013., Report to the

751 National Environmental Research Program. Reef and Rainforest Research Centre

752 Limited, Cairns, p. 52 pp.

753 Muro, M., Jeffrey, P., 2008. A critical review of the theory and application of social

754 learning in participatory natural resource management processes. Journal of

755 Environmental Planning and Management 51, 325-344.

756 Ostrom, E., 2009. Governing the Commons: The Evolution of Institutions for

757 Collective Action. Cambridge University Press.

758 Ostrom, E., Janssen, M.A., Anderies, J.M., 2007. Going beyond panaceas.

759 Proceedings of the National Academy of Sciences of the United States of America $760104,15176-15178$.

761 Pascoe, S., Mary Dichmont, C., Brooks, K., Pears, R., Jebreen, E., 2013.

762 Management objectives of Queensland fisheries: Putting the horse before the 763 cart. Marine Policy 37, 115-122.

764 Pirrone, N., Trombino, G., Cinnirella, S., Algieri, A., Bendoricchio, G., Palmeri, L.,

765 2005. The Driver-Pressure-State-Impact-Response (DPSIR) approach for

766 integrated catchment-coastal zone management: preliminary application to the

767 Po catchment-Adriatic Sea coastal zone system. Regional Environmental Change

$768 \quad 5,111-137$.

769 Rittel, H.W.J., Webber, M.M., 1973. Dilemmas in a general theory of planning.

770 Policy Sciences 4, 155-169.

771 Rowbottom, D.P., Bueno, 0., 2009. How to change it: modes of engagement,

772 rationality, and stance voluntarism. Synthese 178, 7-17. 
773 Saaty, T.L., 1980. The Analytic Hierarchy Process. McGraw-Hill, New York.

774 Sainsbury, K.J., Punt, A.E., Smith, A.D.M., 2000. Design of operational management

775 strategies for achieving fishery ecosystem objectives. ICES Journal of Marine

776 Science 57, 731-741.

777 Smeets, E., Weterings, R., 1999. Environmental indicators: Typology and

778 overview., European Environment Agency Technical Report No. 25. European

779 Environment Agency Technical Report No. 25, Copenhagen. 19pp., p. 19 pp.

780 Smith, A.D.M., Sainsbury, K.J., Stevens, R.A., 1999. Implementing effective

781 fisheries-management systems - management strategy evaluation and the

782 Australian partnership approach. Ices Journal of Marine Science 56, 967-979.

783 Townsend, R., Shotton, R., Uchida, H., 2008. Case studies in fisheries self-

784 governance, FAO Fisheties Technical Paper. FAO, Rome, p. 451.

785 Van Putten, I.E., Dichmont, C.M., Dutra, L.X.C., Thébaud, O., Deng, R.A., Jebreen, E.,

786 Owens, R., Pascual, R., Read, M., Thompson, C., 2015. Objectives for management

787 of socio-ecological systems in the Great Barrier Reef region, Australia. Regional

788 Environmental Change.

789 Van Vugt, M., 2009. Averting the Tragedy of the Commons: Using Social

790 Psychological Science to Protect the Environment. Current Directions in

791 Psychological Science 18, 169-173.

792 Vural-Arslan, T., Cahantimur, A., 2011. Revival of a traditional community

793 engagement model for the sustainable future of a historical commercial district:

794 Bursa/Turkey as a case. Futures 43, 361-373.

795 Walters, C.J., Hilborn, R., 1976. Adaptive control of fishing systems. Journal of the 796 Fisheries Research Board of Canada 33, 145-159. 